\title{
Decision-making and patient's expectations
}

\author{
Robert Gunzburg ${ }^{1}$
}

Received: 1 September 2015/Revised: 1 September 2015/ Accepted: 1 September 2015/Published online: 14 September 2015

(C) Springer-Verlag Berlin Heidelberg 2015

If you did not like a movie, would you want to see the sequel? Or would you readily go back to a restaurant where you did not eat well?

Yet, patients consent to repeat surgery with expectations often as high as for the first surgery. How can we explain that? Of course there are the few who years ago had a successful surgery for a disc herniation, and faced with a new one, are happy to go back under the scalpel, but we all know that these represent only a minority in our field. Did we not generate the term 'failed spine'?

Mancuso et al. [1] performed an in-depth study of patients' expectations in lumbar spine surgery on a large number of individuals and were able to isolate factors influencing their expectations. Of course, like for any study there were limitations and they duly reported them. For one, they drew their population from an urban setting in a tertiary care orthopaedic centre and were limited by the use of English as only accepted language. However, one aspect of their study, although briefly referred to, was not included in the discussion; the difference in expectations according to which surgeon the patients saw. Surely the information given by the treating surgeon will influence the patients' expectations and their consent to surgery (irrespective of whether it is repeat surgery or not)?

Decision-making processes are extremely complex and the result of many internal and external factors. Internal factors are hard to influence; they comprise gender, race, level of education, mood, availability bias, and so on. External factors are of more interest to us as they may be

Robert Gunzburg

robert@gunzburg.be

1 Cavell Spine Centre, Edith Cavell Clinic, Edith Cavell Street 32, 1180 Brussels, Belgium influenced. Here the doctor-patient relationship is of paramount importance.

As this relationship is so influential in the process leading to decision-making on treatment, it surely must have an impact on outcome expectations.

One can surmise that the highest patient satisfaction will be found in patients with the most realistic expectations, irrespectively if they were high or low. Indeed, Palazzo et al. [2] found that surgeon's expectations were predictive of satisfaction and that one should aim at lowering the discrepancy between surgeon's and patient's satisfaction. A surgeon giving more encouraging and optimistic information may have more work, but less satisfied patients than one giving more accurate and realistic information. This topic is scantily reported in the literature and deserves more attention.

\section{Compliance with ethical standards}

Conflict of interest No conflict of interest.

\section{References}

1. Mancuso CA, Duculan R, Stal M, Girardi FP (2015) Patients' expectations of lumbar spine surgery. Eur Spine J. doi:10.1007/ s00586-014-3597-z

2. Palazzo C, Jourdan C, Descamps S et al (2014) Determinants of satisfaction 1 year after total hip arthroplasty: the role of expectations fulfillment. BMC Musculoskelet Disord 15:53 